\title{
Promosi Makanan Halal di Kota Taipei, Taiwan
}

\author{
Mochamad Novi RIfa'i \\ Program Studi Ekonomi Syariah, \\ Universitas Muhammadiyah Malang \\ E-mail: novirifai@umm.ac.id
}

\begin{abstract}
Tulisan ini bertujuan untuk mengetahui penanganan tentang promosi makalan halal di Kota Teipei. Pembahasan tentang makanan halal merupakan bagian penting dari pembahasan kesehatan. Kehalalan makanan dan minuman yang dikonsumsi oleh manusia menjadi salah satu perintah syari'at yang wajib diikuti oleh setiap manusia sebagaimana firman Allah dalam al-Qur'an. Guna menjacapai tujuan penelitian, digunakan metode kualitatif-deskriptif dengan analisis model Spradley, yaitu: setelah menentukan standart makanan dan minuman halal, kemudian dilanjutkan menginventarisir tempat makan halal di Kota Teipei dan melihat konsep makanan halal di lokasi dan kemudian menggali informasi promosi makalan halal di Kota Teipei. Metode pengumpulan data yang digunakan adalah metode pengumpulan data beragam, meliputi: metode observasi, dokumentasi dan wawancara. Halal food merupakan nilai dan norma yang terdapat dalam Hukum Islam terutama yang sangat erat hubungannya dengan perlindungan konsumen, Labelisasi halal sendiri di Kota Taipei Taiwan di keluarkan oleh Taiwan Halal Integrity Development Association (THIDA), Taipei Grand Mosque, CMA dan perorangan muslim. Oleh karena itulah maka diperlukan kajian pemasaran makanan halal di Kota Taipei Taiwan yang implikasinya tidak hanya memudahkan warga Muslim mendapatkan konsumsi halal, namun juga peluang untuk membuka usaha makanan halal yang baru. Sehingga, tujuan dan fokus penelitian ini adalah untuk melihat potensi dan konsep makanan halal serta model promosinya di Kota Taipei Taiwan.
\end{abstract}

Keywords: Promosi, Halal Food, Label Halal.

\section{Pendahuluan}

Makanan merupakan bagian dari kebutuhan pokok bagi manusia. Setelah itu muncul trend makanan menjadi bagian dari pariwisata kuliner, sehingga bukan hanya perihal rasa saja yang diburu, namun juga bentuk dan cara penyajian menjadi hal unik yang layak menjadi tontonan. Menjaga makanan dari hal yang 
haram bagi seorang Muslim merupakan bagian dari ibadah dan iman yang tentunya akan berimplikasi terhadap kebaikan muslim di dunia dan akherat. ${ }^{1}$

Terlepas dari trend makanan menjadi produk wisata, Islam secara jelas telah memberikan perhatian tentang makanan-makanan yang boleh dikonsumsi dan tidak atau makanan yang halal dan haram. Perintah untuk mengkonsumsi makanan halal dan sehat dengan jelas telah termaktub di dalam sumber hokum Islam Al Qur'an (QS. al-Baqarah [2]: 168; 172), QS. An-Nahl [16]: 114; 412); QS. al-Ma'idah[5]: 87; 88), Al-Anfal [8]: 69), sedangkan pengharaman makanan termaktub dalam QS. al-Ma'idah [5]: 3, QS. Al-An'am[6]: 14.

Kota Taipei Taiwan telah memiliki sertifikasi halal yang dikeluarkan oleh beberapa lembaga seperti Halal CMA (Chinesse Muslim Association), Halal Taipei Grand Mosque, dan Taiwan Halal Integrity Development Association (THIDA). Untuk mendapatkan sertifikat halal dari lembaga-lembaga tersebut tentunya ada prosedur serta ketentuan yang harus dipenuhi oleh suatu produk agar masuk kategori halal. Selain aspek kehalalan, konsep promosi produk juga perlu diperhatikan agar ada peningkatan di bidang produksi. Promosi makanan halal diperlukan sebagai penyeimbang komponen dari wisata halal, karena makanan merupakan kebutuhan pokok yang tidak dapat dihindarkan, jika makanan yang disediakan sudah halal maka kebutuhan pokok telah tercukupi.

Berkenaan dengan hubungan antara Indonesia dan Taiwan sebenarnya tidak memiliki hubungan diplomatik, namun walaupun dalam kondisi seperti itu hubungan perekonomian dan pendidikan kedua negara berjalan dengan baik. Pada januari 2016 setidaknya telah tercatat bahwa TKI di Taiwan berjumlah 237.957 orang, dan bagi Taiwan Indonesia merupakan sumber tenaga asing yang paling besar. ${ }^{2}$ Sedang jumlah pelajar berada pada jumlah 5.300 jiwa. Dan menurut Robert kepala Kantor Dagang dan Ekonomi Indonesia bahwa saat ini sedang terjadi pembahasan pengembangan industri halal diatara kedua Negara. ${ }^{3}$

Dalam hubungan perekonomian, Indonesia merupakan mitra dagang ke-12 terbesar Taiwan pada tahun 2014, dan juga merupakan sumber impor ke-9 terbesar serta pasar ekspor ke-14 terbesar. Ekspor utama Taiwan ke Indonesia adalah produk minyak, produk besi dan baja, bahan baku tekstil, bahan kimia, suku cadang mesin dan produk lainnya; Impor utama dari Indonesia adalah gas alam, batubara, paduan tembaga dan emas, kayu dan karet dan bahan baku lainnya. Kerjasama antara perusahaan minyak negara Taiwan CNPC dan BUMN Indonesia telah menandatangani kontrak jangka panjang untuk pengadaan gas alam. Untuk meningkatkan promosi perdagangan antara Taiwan dan Indonesia, Menteri Perekonomian Taiwan bersama-sama dengan organisasi non komersial

\footnotetext{
1 Al-Ghozali, Minhajul Abidin, terj. Nasrullah, (Jakarta: Shahih, 2016), 240. Lihat juga: Gayatri Atmadi, Sri Riris Wahyu Widati, Strategi Pemilihan Media Komunikasi LPPOM MUI Dalam Sosialisasi \& Promosi Produk Halal di Indonesia, Jurnal AL-AZHAR INDONESIA SERI PRANATA SOSIAL, Vol. 2, No. 2, September 2013, 87

${ }^{2}$ www.roc-Taiwan.org/ diakses pada 20 Mei 2018 pada pukul $12.00 \mathrm{WT}$

${ }_{3}^{3}$ www.mediaindonesia.com/ diakses pada $20 \mathrm{Mei} 2018$ pada pukul $12.00 \mathrm{WT}$
} 
mendirikan Taiwan External Trade Development Council (TAITRA) dan di Indonesia sendiri didirikan Taiwan Trade Center, Jakarta. ${ }^{4}$

Dalam hal investasi di Indonesia Menurut data Badan Koordinasi Penanaman Modal Indonesia (BKPM) sampai pada akhir tahun Desember 2015, jumlah investasi Taiwan di Indonesia mencapai USD 17,097,000,000. Banyaknya investasi adalah 1.766 buah. Jenis investasi utama adalah industri mebel, industri sepatu, industri tekstil, industri pertambangan non logam, industri logam, industri roda ban, layanan perdagangan, pertanian dan lainnya. ${ }^{5}$ Menurut data imigrasi Indonesia, saat ini jumlah pengusaha Kota Taiwan dan teknisi Taiwan yang bekerja di Indonesia cukup banyak yaitu sekitar 10.000 orang, jumlah perusahaan Kota Taipei Taiwan lebih dari 2.000. Perusahaan besar Taiwan terdiri dari: Bank CTBC Indonesia, perusahaan sepatu Bao Cheng, Nan Ya Plastics Corporation , Acer Inc, ASUS, Fengtay, Les Enphants, Tainan Enterprises Co. Ltd, Makalot Industrial Co. Ltd, TECO, TATUNG, Uni President Corps, Restoran Din Tai Fung, E United Group, Maxxis, KENDA Rubbers dan lainnya. Kerjasama yang terjalin dengan baik di segala bidang ini tentunya merupakan lahan ekonomi yang patut untuk dikembangkan.

Berdasarkan perkembangan jumlah penduduk dunia, setiap tahun terjadi peningkatan kisaran 1,8\% jumlah penduduk muslim, sehingga diperkirakan jumlah umat muslim sebanyak $25 \%$ dari seluruh populasi umat beragama di dunia. Jumlah tersebut menunjukkan bahwa market size makanan halal di dunia sangat tinggi sehingga Produk konsumsi halal saat ini tidak hanya laris di negaranegara Muslim atau mayoritas berpenduduk muslim saja, namun juga negaranegara lainnya, termasuk Kota Taipei Taiwan. ${ }^{\mathbf{6}}$

Seiring dengan semakin meningkatnya market size industri makanan halal di Kota Taipei Taiwan, maka penyediaan makanan halal juga semakin bertambah. Banyaknya persediaan makanan halal tentu menjadi kewajiban perusahaan atau manajemen untuk melakukan promosi berkenaan dengan produk halal yang dimilikinya agar diminati oleh pasar. Promosi merupakan bagian dari bauran pemasaran. Semakin betumbuhnya jumlah penduduk muslim, maka kegiatan promosi makanan halal harus semakin gencar dilakukan untuk menjemput pembeli fanatik. Di lain sisi, kegiatan promosi sebaiknya juga tidak hanya memuaskan needs dan wants dari konsumen fanatik semata, namun harusnya juga bisa menjadikan produk halal life-style, sehingga konsumen merasa lebih sehat dan bernilai dibandingan menkonsumsi barang lain. Konsep pemasaran promosi sendiri terdiri dari: advertising, personal selling, sales promotion, merchandising, public relations and publicity. ${ }^{7}$ Ketika melihat kondisi di Kota

\footnotetext{
${ }^{4}$ http://jakarta.Kota Taipei Kota Taipei Taiwantrade.com.tw// Diakses pada 20 Mei 2018 pada pukul 12.00 WT

${ }^{5}$ https://www.roc-Kota Taipei Taiwan.org/. Diakses pada 20 Mei 2018 pada pukul 12.00 WT

6 ITCP, Osaka, Market Brief: Halal Product, 2013, 6

${ }^{7}$ Agung Permana Budi, Manajemen Marketing Perhotelan, (Yogyakarta: Andi, 2013), 30
} 
Taipei Taiwan dengan jumlah penduduk Muslim yang terus berkembang dan meningkatnya kesadaran akan kesehatan makanan halal maka menjadi menarik untuk membahas model promosi makanan halal di Kota Taipei Taiwan.

Berdasarkan uraian diatas, maka diperlukan kajian mendalam tentang konsep makanan halal dan model promosi makanan halal di Kota Taipei Taiwan. Dengan pendekatan produk maka diharapkan akan semakin muncul lebih banyak fariasi makanan halal. Tujuan dan fokus kajian ini adalah melihat potensi makanan halal di Kota Taipei Taiwan dan konsep promosi makanan halal di Kota Taipei Taiwan, sehingga bisa memberikan masukan untuk perkembangan halal food di Taipei.

\section{Konsep Makanan Halal}

Secara bahasa halal diartikan sebagai sesuatu yang diizinkan atau dibolehkan. Sedang makanan berarti memasukkan sesuatu ke dalam mulutdalam bahasa Arab makanan disebut dengan $a l$-tho' $\mathrm{am}^{8}$. Secara istilah makanan halal artinya adalah makanan yang boleh dikonsumsi menurut al-Quran dan hadits. Intinya makanan halal adalah makanan baik yang dibolehkan memakannya menurut ajaran Islam, yaitu sesuai dalam al-Quran dan hadis. Salah satu kaidah utama dalam hal muamalah adalah segala sesuatu itu boleh untuk di konsumsi sampai ada dalil yang mengharamkan. ${ }^{9}$ Dari kaidah tersebut terlihat bahwa makanan yang halal lebih banyak daripada makanan yang haram, hal tersebut ditegaskan oleh Allah SWT dalam QS. Al-Baqaroh[2]: 29), disampaikan bahwasanya Allah SWT telah menciptakan semua yang ada di bumi untuk manusia. Di dalam alquran Allah SWT banyak mempertegas perhatiannya akan aktifikas konsumsi dan apa yang di konsumsi, hal tersebut terlihat dari pembahasan makanan sebanyak 48 kali, kata kerja makan sebanyak 109 kali, perintah makan sebanyak 27 kali dan aktifitas minum sebanyak 39 kali. ${ }^{10}$

Pada QS. Al-Maidah ayat 88 Allah SWT memerintahkan supaya manusia memakan makanan yang halal dan baik (thoyyib). Kata thoyyib setelah kata halal menandakan bahwa manusia harus memakan makanan yang baik bagi tubuhnya, maknanya adalah manusia tidak boleh mengkonsumsi sesuatu yang membahayakan bagi tubuhnya. Thoyyib sendiri menurut Nurdin berarti kebaikan, kebajikan atau keberkahan. ${ }^{\mathbf{1 1}}$ Menurut Yusuf Qardhawi thoyyib dimaknai dengan makanan yang proposional mengundang selera bagi yang memakannya, atau tidak membahayakan fisik atau akalnya. ${ }^{\mathbf{1 2}}$ Bahasan tentang makanan yang haram sendiri di dalam al-Quran sendiri hanya terdapat 4 (empat) macam makanan seperti yang tertulis dalam QS. Al-Baqarah[2]: 173 yaitu: bangkai, darah, babi dan makanan yang tidak disembelih dengan nama Allah. Sedangkan makanan haram

\footnotetext{
${ }^{8}$ Muhammad Yunus, Kamus Arab Indonesia, Yayasan Penyelenggara Penterjemah alQuran. (Jakarta: tp, 1973), 101

${ }^{9}$ Yusuf Qardhawi, Halal Haram Dalam Islam. (Solo: Era Intermedia, 2003), 36. Lihat juga: Abdul Wahhab Khallaf, Ilmu Ushul Fiqh. Cet.1, (Semarang: Dina Utama, 1994), 127

${ }^{10}$ Tiench Tirta Winata, Makanan dalam Perspektif alqurandan Ilmu Gizi, (Jakarta: Balai Penerbit FKUI, 2006), 1

${ }^{11}$ Kamaluddin Nurdin Marjuni, Kamus Syawarifiyyah: Kamus Modern Sinonim ArabIndonesia. (Jakarta: Ciputat Press Group, 2007), 401

${ }^{12}$ M. Quraish Shihab, Wawasan alquran. (Bandung: Mizan, 2000), 148-150
} 
menurut hadits yakni: hewan buas yang bertaring, burung yang memiliki cakar, keledai yang jinak. ${ }^{\mathbf{1 3}}$

\section{Konsep Promosi}

Promosi merupakan salah satu cara untuk meningkatkan penjualan suatu produk. Dengan adanya promosi maka konsumen teredukasi suatu produk secara detil mulai dari kelebihan dan kekurangan, harga dan keutungan jika membeli barang tersebut. Semakin banyak masyarakat teredukasi produk halal maka semakin banyak potensi konsumen yang membeli produk halal, dan tentu berimbas kepada profit dari pengusaha produk halal. ${ }^{14}$ Di dalam buku Oesman, Kotler \& Keller, Zeithaml, Bitner \& Gremler mengemukakan bahwa konsep bauran pemasaran tradisional terdiri dari 4P, yaitu produk (product), harga (price), tempat (place), dan promosi (promotion). Namun berkenaan dengan bauran pemasaran jasa menurut Seiring dengan pendapat diatas Zeithaml, Bitner \& Gremler, Lovelock \& Wirtz perlu menambahkan unsur orang (people), proses (process) dan bukti fisik (physical evidence). ${ }^{15}$ Konsep pemasaran promosi diantaranya: advertising, personal selling, sales promotion, merchandising, public relations and publicity dengan definisi sebagai berikut: ${ }^{16}$

a) Advertising (Perikalanan): menyampaikan informasi produk melewati berbagai macam media

b) Personal Selling: Penjelasan secara langsung kepada calon pembeli

c) Sales Promotion: Keinginan menawarkan secara insetif agar calon pembeli segera mengambil keputusan untuk membeli produk.

d) Merchandising: kesedian stock untuk melayani pembelian sewaktuwaktu.

e) Public Relation: kegiatan menciptakan hubungan yang baik dengan masyarakat agar perusahaan atau produk memiliki image yang baik.

f) Publicity (publisitas): pemuatan berita tentang produk pada penerbitan majalah atau koran, radio, atau televisi.

Promosi sendiri memiliki beberapa tujuan memodifikasi tingkah laku, memberitahu dan membujuk calon konsumen atas barang yang sedang di promosikan. ${ }^{17}$ Dengan kegiatan interaksi tersebut harapannya bahwa barang yang di promosikan dibeli oleh konsumen sesuai dengan harga yang ditawarkan. Menurut Abuznaid etika promosi yang dilakukan dalam islam yakni tidak diperbolehkannya melakukan pelecehan terhadap suku, agama dan ras, eksploitasi perempuan dalam iklan, penggunaan fantasi yang berlebihan dan penggunaan perempuan sebagai pemikat dan menarik pelanggan. ${ }^{18}$

\footnotetext{
${ }^{13}$ Muchtar Ali, Konsep Makanan Halal dalam Tinjauan Syariah dan Tanggung Jawab Produk atas Produsen Industri Halal, Jurnal Ahkam Vol. xVI, No 2, Juli 2016, 295

${ }^{14}$ Heindjrachman Ranupandojo, Dasar-Dasar Ekonomi Perusahaan, (Yogyakarta: UPP AMP YKPN, 1990), 7

15 Yevis Oesman. Sukses Mengelola Marketing Mix CRM Customer Value dan Customer Dependency (Kasus Pada Pemasaran Shopping Center). (Bandung: Alfabeda, 2010), 22

${ }^{16}$ Agung Permana Budi, Manajemen Marketing Perhotelan,.. 32

${ }^{17}$ Marwan Asri, Marketing, (Yogyakarta: UPP-AMP YKPN, 1991), 361

${ }^{18}$ Nur Asnawi dan Muhammad Asnan Fanani, Pemasaran Syariah, Teori, Filosofi, dan Isu-isu kontemporer (Depok: Rajawali Press, 2017), 168
} 
Berpromosi merupakan upaya mengenalkan produk kepada calon pembeli, namun perlu diingat bahwa Islam melarang memberikan informasi yang berlebihan karena hanya akan mendatangkan kekecewaan calon pembeli dan kualitas penjualan di masa mendatang. Kegiatan promosi yang dilakukan hendaknya tidak bertentangan dengan kondisi barang yang ditawarkan, tindakan promosi yang berlebihan terhadap suatu barang justru akan menyebabkan reputasi pedagang menurun, sehingga barang apapun yang dipromosikan pada masa mendatang akan menjadi berkurang nilainya dihadapan calon pembeli.

\section{Penduduk Taipei}

Dengan Luas $36.193 \mathrm{~km} 2$ Taiwan memiliki Jumlah total warga 23.52 juta jiwa, yang terdiri dari 95\% dari suku hand 5\% lainnya dari AustronasionAgama yang dipeluk oleh warga juga berbagai macam yakni : Budha, Tao, Budaya China, Katolik, Protestan dan Islam. Sebagai pusat perkotaan di Taiwan, Secara umum warga Taipei tidak terlalu memperhatikan soal agama. Agama merupakan urusan pribadi masing-masing. Bahkan terhadap anakpun mereka kebanyakan masih tidak terlalu mendidik agama sesuai tuntunan agama yang dianut oleh orang tua.

Hal tersebut diatas dipertegas diungkapkan oleh shanto, bahwa: "Orang Taiwan itu mereka bebas terhadap agama, mereka gak terlalu mikir soal agama. Pokoknya orang itu gak gannggu kepentingan umum ya jalan aja silahkan." Senada dengan apa yang di sampaikan shanto, nuril seorang pekerja yang udah tinggal lama di Taipei menyampaikan juga, "kebanyakan orang Taipei itu atheis, makanya mereka belajar dengan tujuan semua kehidupan bisa dinalar atau dipikirkan. Mereka kebanyakan tidak mau bersandar hidup terhadap agama yang ada."

Ketika penulis melihat dan menghadiri pemakaman warga Muslim di Taipei, ternyata yang disampaikan oleh nara sumber diatas tidakklah salah. Ketika ada warga Muslim yang meninggal selain sebagai bentuk penghormatan kepada jenazah yang semasa hidupnya beragama Islam mereka hanya menyerahkan kepada masjid untuk di uruskan perawatan jenazahnya, karena mereka tidak tahu cara perawatan jenazah secara Islam. Begitu juga ketika saat pemakaman, yang hadir pun dari keluarga hanya melihat jenazah di letakkan diliang kubur, setelah itu mereka pergi kembali ke rumah. Jika melihat pasar malam di Taipei maka terlihat banyak sekali penjaja makanan baik yang kategori halal maupun haram. Kebanyakan makanan halal belum memiliki label resmi halal dari lembaga halal manapun, contohnya seperti makanan-makanan vegetarian dan jajanan fast food lainnya. Kondisi tersebut bisa jadi dikarenakan belum memiliki modal untuk membuat label halal di lembaga resmi. Ada juga beberapa toko yang telah memiliki label friendly halal dari lembaga-lembaga resmi. Friendly halal ini artinya pemilik dari toko tersebut adalah seorang non Muslim, tapi makanan yang dijual halal sesuai standart halal. Tampak terlihat bahwa toko-toko tersebut juga ramai pengunjung bukan saja oleh pembeli Muslim namun pembeli non Muslim karena makanan yang dijual tersebut memiliki keunikan tersendiri dengan tetap menjaga kehalalan. 


\section{Model Promosi Makanan Halal di Taipei}

Bagi produsen makanan atau minuman, pemberian label halal merupakan salah satu tahapan yang harus dilalui jika makanan dan minuman produksinya ingin menyasar pasar umat Islam, terlebih jika para produsen ingin mengirim produk mereka ke negara-negara Islam. Secara khusus pemerintah tidak mengatur tentang pelebelan halal, sehingga kelompok-kelompok Islam yang ada di Taipei boleh mengeluarkan lebel halal. Senyampang yang terlihat label halal di Taipei dikeluarkan oleh beberapa kelompok, yakni MCA (Muslim Chinese Asotiation), Taipei Grand Mosque, THIDA dan Lembaga Pribadi, bahkan peneliti pernah melihat juga label halal yang dikeluarkan oleh Nahdhatul Ulama cabang Taipei.

Bagi produsen yang non Muslim juga tidak tertutup kesempatan untuk berdagang makanan halal dengan label halal dari lembaga-lembaga resmi yang biasa juga disebut dengan friendly halal. Kemauan non Muslim untuk berdagang makanan halal ini menandakan bahwa halal food market memang menarik untuk diupayakan dan merupakan lahan bisnis yang menjanjikan keuntungan.

Di Kota Taipei Taiwan sendiri makanan halal telah dengan mudah dapat ditemukan seiring dengan kebijakan pemerintah memunculkan pariwisata yang ramah bagi umat Muslim, mengingat jumlah umat Islam sendiri dengan pemeluk 1600 Milyar di seluruh dunia. Namun nyatanya menurut Maha M. Hadi, sekarang halal bukan hanya dilihat dari cara mendapatkan dan obyek yang dikonsumsi, ternyata faktor asupan makanan obyek yang dimakan juga harus menjadi pertimbangan dalam penentuan halal atau haram. Produk makanan halal menurut lokasinya dibagi menjadi dua, yakni makanan halal yang telah memiliki lokasi dagang tetap dan makanan yang dijual bebas. Makanan yang telah memiliki lokasi tetap biasanya mudah untuk di kenali karena tempat penjualannya mudah dituju oleh calon konsemen. Berbeda dengan makanan yang di jual bebas, mereka perlu pengenalan rutin agar produk dikenal oleh masyarakat.

Makanan yang telah memiliki lokasi tetap seperti: Ai-Jia Muslim beef noodles restaurant, Abad Indian Kitchen, Aki Kusa Japanese Restaurant, Alibaba Indian Kitchen, Alla-din Indian Pakistan Halal Food, Arabian Night Taiwan, Azees Indian Food, Cassablanca Morocco Deli, Chang Beef Noodle Shop, City Kebab, Dingxian 101, Fried Chicken Master Gongguan, Fried Chicken Master Nangang, Gusto Pizza, Halla Bismillah Restaurant, Halal Curia, Halal Tai Huang Restaurant, Hui Guan, Ice Monster, Jaish Indian Restaurant, Kunming Islamic Food, Khana Khazana Indian Pakistani, Masala Art and Masala Zone Restaurant, Pharaohs Egyptian, Really Good Seafood, Royal Cafe, Sathiya Indian Cuisine, Taj Indian Restaurant, Tandoori, Thai Wang Thai Muslim Food, Toko Indonesia al Muttaqin Yonghe, Toko Sakura XinSheng. Sedangkan makanan yang tidak memiliki lokasi penjualan dan harus kerjasama dengan supermarket dan minimarket sangat banyak sekali, seperti: Pak Fah Yeow, UTC Foods, TSC (Taiwan Sugar Corporation), Sheng Fang Tea, Pei Tien, Lucky Holder dan banyak lagi makanan halal yang dieksport.

Adapun model pemasaran makanan halal di Taipei adalah sebagai berikut:

a) Advertising (iklan)

Penelitian yang dilakukan menunjukkan bahwa bauran promosi iklan/advertising nampak belum kompak dilakukan oleh produk-produk halal. Bisa jadi ketimpangan tersebut disebabkan oleh biaya iklan yang 
mahal sehingga tidak semua produk halal minat untuk melakukannya atau bisa jadi karena segmen sasaran yang dituju tidak sesuai dengan produk.

Upaya promosi yang dilakukan selama ini sebatas individu dan belum belum tampil maksimal dalam media-media. Baliho atau banner yang dipasang juga dinilai masih kurang tepat dan kurang strategis penempatannya. Rekomendasi peneliti alangkah baiknya jika iklan yang dibuat melalui booklet produk halal dengan payung lembaga halal masingmasing kemudian disebar di titik-titik tertentu seperti pariwisata dan komunitas umat Islam agar tepat pada sasaran. Iklan yang dilakukan oleh produk halal hendaknya bisa memberikan kesan mendalam mulai dari harga yang kompetitif, manfaat dari produk halal itu sendiri, jaminan mutu perusahaan yang tidak meragukan, atau bahkan produk halal tersebut juga memiliki prestige dibandingkan produk lain.

b) Personal Selling, (penjualan pribadi)

Penjualan dengan model Personal Selling tidak terlalu dioptimalkan, dikarenakan pendekatan secara personal hanya menghabiskan biaya dan waktu. Sehingga personal selling yang dilakukan dengan masuk ke kelompok-kelompok Islam yang berada di Taipei. Di lain sisi Sumber Daya Manusia yang melakukan personal selling tentunya perlu dipersiapkan dengan baik dan menguasai konsep produk halal, bukan hanya sekedar kemampuan penjualan saja. Sentuhan personal selling harapannya dapat memberikan appeal tersendiri bagi konsumen produk halal.

c) Sales Promotion, (promosi dengan sales)

Promosi Penjualan/ Sales Promotion telah dilakukan lewat eventevent, serta bekerjasama dengan Dinas pariwisata dan biro-biro pariwisata. Hal ini tentunya perlu ditingkatkan sehingga hasilnya lebih efektif. Penawaran yang dilakukan tentunya bukan hanya sekedar menawarkan produk halalnya saja namun juga kelebihan-kelebihan dari produk halal tersebut agar konsumen non Muslim juga bisa tertarik untuk menikmatinya. Di supermarket atau mini market yang ada, produk halal masih berbaur dengan produk haram, sehingga menyulitkan bagi wisatawan yang belum bisa bahasa mandarin, atau pembeli produk halal akan membutuhkan waktu lama untuk mencari produk halal yang diinginkan. Dari pengamatan yang dilakukan tersebut maka hendaknya promosi penjualan mampu bekerjasama dengan produk halal yang lain sehingga posisi produk-produk halal yang ada dijadikan satu pada posisi tertentu sehingga memudahkan pembeli untuk memilih produk halal yang diinginkan.

d) Public relations (hubungan masyarakat)

Pengembangan promosi lewat public relation telah dilakukan oleh sebagian produk-produk halal dengan ikut bergabung dalam penyelenggaraan-penyelenggaraan event keagamaan atau kemasyarakatan yang diselenggarakan di Kota Taipei seperti universarty Taipei Grand 
Mosque dan peringatan hari besar keagamaan Islam yang memang menjadi magnet umat Islam berkumpul.

e) Publicity (publikasi)

Produk-produk halal di Taipei belum menjalankan fungsi publikasi dengan optimal lewat publikasi media cetak untuk menarik pembeli. Publikasi yang mudah dan cepat ke sasaran saat ini dilakukan lewat media on line. Dibandingkan dengan promosi publikasi, kekuatan promosi dari mulut ke mulut komunitas Muslim masih menjadi kekuatan dalam penjualan produk halal.

Sedangkan faktor-faktor pendukung dan penghambat promosi pengembangan produk halal dalam meningkatkan penjualan produk halal adalah sebagai berikut:

a) Faktor Pendukung

1) Faktor Internal

Faktor pendukung secara internal dalam pengembangan promosi produk halal adalah dari kaum Muslim sendiri yang memang membutuhkan produk halal sebagai konsumsi sehari-hari, organisasiorganisasi Islam juga turut mendukung dengan melibatkan produkproduk halal disetiap event-event yang diadakan.

2) Faktor Eksternal

Faktor pendukung yang berasal dari eksternal dalam upaya pengembangan promosi meningkatkan penjualan adalah bantuan pemerintah lewat Dinas perdangan dan dinas pariwisata yang turut juga mempromosikan produk halal secara keseluruhan dalam usaha menarik wisatawan dari Timur Tengah maupun wisatawan muslim, sehingga muncul slogan Taipei Friendly Muslim.

b) Faktor Penghambat

1) Faktor Internal

Faktor penghambat dari internal terkait dengan edukasi tentang Islam untuk para pekerja halal food, karena selama ini halal banyak dimaknai hanya daging babi atau bahkan beranggapan turunan dari bahan babi tidak haram. Selain itu edukasi tentang manfaat makanan halal dan bahaya makanan haram perlu digencarkan agar makanan halal bukan hanya dikonsumsi oleh umat Islam, namun juga non Muslim.

2) Faktor Eksternal.

Stigma Islam sebagai agama teroris masih menjadi anggapan beberapa warga, sehingga berdampak juga pada produk Muslim. Namun seiring dengan perkembangan waktu, penjelasan Islam sebagai agama rahmatan lil alamin terus banyak dilakukan, salah satunya dengan adanya Taipei Grand Mosque yang menjadi museum di tengah kota menjadi bukti keharmonisan muslim dan penduduk lokal dan bahkan masjid terbuka untuk umum jika ingin mengetahui info tentang Islam.

\section{Kesimpulan}


Makanan halal di Taipei merupakan makanan yang telah sesuai dengan aturan bahan dan pengolahan menurut Alquran dan Alhadits. Legal formal yang menyebutkan kehalalan makanan halal bisa di butktikan dengan sertifikat halal yang dikeluarkan oleh lembaga-lembaga Muslim resmi seperti THIDA, CMA dan Taipei Grand Mosque. Sedangkan bauran promosi yang telah dilakukan saat ini lebih banyak pada bauran promosi Sales Promotion, Public Relation dan publikasi on line dikarenakan lebih murah dan mudah diakses oleh calon pembeli, sedangkan bauran pemasaran lewat iklan masih belum dilirik secara maksimal karena memang biaya yang dikeluarkan harus lebih besar. Untuk mendapatkan trend yang bagus tentang halal food, peningkatan kerjasama promosi produk halal harus bisa terjalin sehingga label halal bisa menjadi kekuatan tersendiri di hati masyarakat. Jika kerjasama bisa terjalin maka promosi penjualan di supermarket ataupun mini market dapat dioptimalkan lewat rak halal tersendiri pada display makanan dan minuman halal.

\section{Daftar Pustaka}

Al-Ghozali, minhajul abidin, terj.Nasrullah Jakarta: Shahih, 2016.

Asnawi, Nur dan Muhammad Asnan Fanani, Pemasaran Syariah, Teori, Filosofi, dan Isu-isu kontemporer Depok: Rajawali Pers, 2017.

Atmadi, Gayatri, Sri Riris Wahyu Widati, Jurnal AL-AZHAR INDONESIA SERI PRANATA SOSIAL, Vol. 2, No. 2, September 2013, Strategi Pemilihan Media Komunikasi LPPOM MUI Dalam Sosialisasi \& Promosi Produk Halal di Indonesia.

Ali, Muchtar, Konsep Makanan Halal dalam Tinjauan Syariah dan Tanggung Jawab Produk atas Produsen Industri Halal, Jurnal Ahkam Vol. XVI, No 2, Juli 2016.

Asri, Marwan, Marketing, Yogyakarta: UPP-AMP YKPN, 1991.

Budi, Agung Permana, Manajemen Marketing Perhotelan, Yogyakarta: Andi, 2013.

ITCP, Osaka, Market Brief: Halal Product, 2013.

Khallaf, Abdul Wahhab, Ilmu Ushul Fiqh. Cet.1, Semarang: Dina Utama, 1994.

Marjuni, Kamaluddin Nurdin, Kamus Syawarifiyyah: Kamus Modern Sinonim Arab-Indonesia. Jakarta: Ciputat Press Group, 2007.

Oesman, Yevis. Sukses Mengelola Marketing Mix CRM Customer Value dan Customer Dependency (Kasus Pada Pemasaran Shopping Center). Bandung: Alfabeda. 2010.

Proyek Perguruan Tinggi Agama /IAIN di Pusat Direktorat Pembinaan Perguruan Tinggi Agama Islam, Ilmu Fiqih. Jakarta: tp, 1982.

Qardhawi, Yusuf, Halal Haram Dalam Islam. Solo: Era Intermedia, 2003.

Ranupandojo, Heindjrachman, Dasar-Dasar Ekonomi Perusahaan, Yogyakarta: UPP AMP YKPN, 1990.

Shihab, M. Quraish, Wawasan alquran. Bandung: Mizan, 2000

Winata, Tiench Tirta, Makanan dalam Perspektif al-Quran dan Ilmu Gizi Jakarta: Balai Penerbit FKUI, 2006. 
Yunus, Muhammad, Kamus Arab Indonesia, Yayasan Penyelenggara Penterjemah al-Quran. Jakarta: tp, 1973

https://english.ey.gov.tw/cp.aspx?n=D79AEEED26A1B0FE diakses pada 20 Mei 2018 pada pukul 12.00 WT

http://jakarta.Kota Taipei Kota Taipei Taiwantrade.com.tw/ diakses pada 20 Mei 2018 pada pukul $12.00 \mathrm{WT}$

https://www.roc-Kota Taipei Taiwan.org/ diakses pada 20 Mei 2018 pada pukul $12.00 \mathrm{WT}$ 